\title{
Risk Factors for Dose Reduction of Pirfenidone in Patients With Idiopathic Pulmonary Fibrosis: a Study Based on Real-world Clinical Data
}

\section{Jiwon Kim}

University of Ulsan College of Medicine, Asan Medical Center

Chiwook Chung

University of Ulsan College of Medicine, Asan Medical Center

Hyo Sin Cho

University of Ulsan College of Medicine

Ho Cheol Kim ( $\square$ kimhocheol10@gmail.com )

University of Ulsan College of Medicine, Asan Medical Center

\section{Research Article}

Keywords: risk factor, pirfenidone, idiopathic pulmonary fibrosis, real-world data

Posted Date: January 20th, 2022

DOI: https://doi.org/10.21203/rs.3.rs-1262100/v1

License: (c) (i) This work is licensed under a Creative Commons Attribution 4.0 International License.

Read Full License 


\section{Abstract}

Background Although pirfenidone slows disease progression in patients with idiopathic pulmonary fibrosis (IPF), patients often cannot tolerate the recommended dose of pirfenidone because of several adverse events in clinical practice. This study aimed to investigate adverse events associated with pirfenidone and the risk factors in patients requiring dose reduction.

Methods This single center retrospective cohort study included 156 consecutive patients with IPF who received pirfenidone. Demographic characteristics, pulmonary function, and pirfenidone-related adverse events were investigated. We compared patients who received standard and reduced dose of pirfenidone.

Results The mean age of patients was 69.7 years. The median follow-up duration was 243 days. The low dose group $(\mathrm{n}=99)$ comprised older patients (71.0 vs. 67.4 years, $p=0.012)$, fewer smokers $(79.8 \%$ vs. $96.4 \%, p=0.004$ ), and patients with lower body mass index (BMl; 24.2 vs. 25.7, $p=0.020$ ) compared with the standard dose group $(n=57)$. Multivariate logistic regression analysis revealed that older age (odds ratio $=1.060, p=0.014$ ) was significantly associated with dose reduction of pirfenidone after adjusting for sex, smoking history, and BMI. No significant difference was found in the reduction rate of forced vital capacity $(p=0.260)$ and diffusing capacity for carbon monoxide $(p=0.186)$ between the standard and low dose groups.

Conclusions Although older patients are more likely to undergo dose reduction of pirfenidone, low dose pirfenidone is effective for treating patients with IPF. Low dose pirfenidone can be considered an effective treatment option for older patients with IPF.

\section{Background}

Idiopathic pulmonary fibrosis (IPF) is a chronic, progressive, and fibrotic interstitial lung disease [1]. The clinical course of IPF is highly variable and unpredictable, with a median survival of 3-5 years after diagnosis [2,3].

The antifibrotic drug, pirfenidone, reduces lung function decline in patients with IPF compared with placebo $[4,5]$ and is used in clinical practice [6, 7]. In addition, several recent studies have reported that pirfenidone might reduce mortality in patients with $\operatorname{IPF}[8,9]$.

However, it is well known that pirfenidone may cause side effects. Gastrointestinal- and skin-related events are common side effects of pirfenidone $[4,5,10,11]$. In clinical trial in Japan, the efficacy of 1800 $\mathrm{mg} /$ day pirfenidone was evaluated, which was lower than that administered ( $2403 \mathrm{mg} /$ day) in the United States, Europe, Australia, and North America. However, the dose of 1800 mg/day was thought to be comparable to $2403 \mathrm{mg} /$ day on weight-normalized basis [5, 12]. According to a recent post-marketing surveillance (PMS) study in Korea, $86.3 \%$ of patients experienced adverse events [13], suggesting that the number of side effects of pirfenidone is likely to be higher in Asia, especially in real-world practice than in randomized controlled trials (RCTs). 
Even though some studies have reported that a low dose of pirfenidone group is not inferior to a standard dose[12, 14, 15], there are few reports focused on the side effects associated with pirfenidone and reduced doses. Thus, we aimed to investigate clinical characteristics and risk factors associated with dose reduction of pirfenidone in a real-world setting.

\section{Method}

\section{Patients and settings}

This single center retrospective cohort study enrolled patients with IPF from the Asan Medical Center, Seoul, Republic of Korea. Patients who started pirfenidone therapy between August 2017 and July 2021 were identified using electronic medical records (EMRs).

Inclusion criteria were as follows: (1) diagnosis of IPF, (2) treatment with pirfenidone, and (3) at least one followed up after taking pirfenidone to assess the occurrence of adverse events. IPF was diagnosed based on the American Thoracic Society/European Respiratory Society/Japanese Respiratory Society/Latin American Thoracic Association guidelines published in 2018 [1].

Demographic and clinical data, including age, sex, body mass index (BMI), smoking status, comorbidities, concurrent medication, pulmonary function test (PFT) result, six-minute walk test (6MWT) result, highresolution computed tomography (HRCT), echocardiogram findings, prescribing information for pirfenidone therapy, reasons for dose reduction, and adverse events, were collected from EMRs. Spirometry was performed and diffusing capacity of the lungs for carbon monoxide (DLCO) was measured. Pulmonary hypertension was diagnosed based on echocardiographic evidence: maximal tricuspid regurgitation velocity (TR Vmax) $>3.4 \mathrm{~m} / \mathrm{s}$ or estimated systolic pulmonary arterial pressure $>40$ $\mathrm{mmHg}[16,17]$.

The study was conducted in accordance with the tenets of the Declaration of Helsinki. The study protocol was approved by the Institutional Review Board of Asan Medical Center (IRB number: 2021-0787). The requirement for informed consent was waived because of the retrospective nature of the study and use of anonymized clinical data for analysis.

\section{Pirfenidone dose}

Patients diagnosed with IPF were initially prescribed $600 \mathrm{mg} /$ day pirfenidone. The dose was increased every 1-2 weeks until $1800 \mathrm{mg} /$ day. The patients were divided into the following two groups: treated with pirfenidone at a standard dose ( $1800 \mathrm{mg} /$ day) and treated with at a low dose ( $<1800 \mathrm{mg} / \mathrm{day})$. The standard dose group comprised patients who continued taking the standard dose of pirfenidone (1800 $\mathrm{mg} /$ day) after dose escalation. The low dose group comprised patients who did not receive higher doses of the drug (maximum: standard dose [1800 mg/day]), who reduced the dose of the drug, and who discontinued the drug.

\section{Statistical analysis}


The baseline characteristics of all patients are presented as number (percentage; categorical variables) or mean \pm standard deviation (continuous variables). Continuous and categorical variables were compared between the groups using an independent $t$ test and the Fisher's exact test or Pearson's chi-square test, respectively. Univariate and multivariate logistic regression analysis were performed to evaluate the risk factors for the dose reduction of pirfenidone.

In addition, a linear mixed model was used to compare the treatment effect according to the dose of pirfenidone. Forced vital capacity (FVC) and DLCO data of patients who underwent at least two PFTs after receiving pirfenidone were used for analysis.

Statistical analysis was performed using SPSS version 26 . A $p$ value of $<0.05$ was considered statistically significant.

\section{Results}

\section{Characteristics}

This study included 156 patients who received pirfenidone treatment for IPF. The median follow-up period was 243 days (interquartile range [IQR]: $84-385$ days). The mean age of patients was 69.7 years. A total of $90.4 \%$ patients were male and $85.8 \%$ were ever-smokers (Table 1 ). Study population classification by pirfenidone dose and maintenance is summarized in Figure 1. A total of $26(28.8 \%)$ patients discontinued pirfenidone treatment during the follow-up period and 99 (63.5\%) patients did not receive higher than initial dose or received a reduced pirfenidone dose were classified into the low dose group.

The low dose group $(\mathrm{n}=99)$ comprised older age patients (71.0 vs. 67.4 years, $p=0.012)$, fewer smokers (79.8\% vs. $96.4 \%, p=0.004)$, and patients with lower BMI ( 24.2 vs. $25.7, p=0.020)$ compared with the standard dose group $(n=57)$ (Table 1). No significant difference was found in baseline PFT, exercise capacity, and cancer history between the two groups. In addition, no significant difference was found in the rate of pulmonary hypertension between the two groups; however, patients in the standard dose group had emphysema $(p=0.091)$, unlike those in the low dose group. Data regarding emphysema and pulmonary hypertension in patients who underwent serial PFT are presented in Supplementary Table 1.

Table 1. Baseline characteristics of patients 


\begin{tabular}{|c|c|c|c|c|}
\hline & $\begin{array}{l}\text { Total } \\
(n=156)\end{array}$ & $\begin{array}{l}\text { Standard dose } \\
\text { group } \\
(n=57)\end{array}$ & $\begin{array}{l}\text { Low dose } \\
\text { group } \\
(n=99)\end{array}$ & $P$ value \\
\hline Age, years & $69.7 \pm 8.5$ & $67.4 \pm 9.6$ & $71.0 \pm 7.6$ & 0.012 \\
\hline Male, n (\%) & $141(90.4)$ & $55(96.5)$ & $86(86.9)$ & 0.050 \\
\hline Ever smoker, n (\%) & $133(85.8)$ & $54(96.4)$ & $79(79.8)$ & 0.004 \\
\hline $\mathrm{BMI}, \mathrm{kg} / \mathrm{m}^{2}$ & $24.7 \pm 4.0$ & $25.7 \pm 4.9$ & $24.2 \pm 3.3$ & 0.020 \\
\hline Diagnosis & & & & 0.223 \\
\hline Biopsy proven, n (\%) & $23(14.7)$ & $11(19.3)$ & $12(12.1)$ & \\
\hline Clinical, n (\%) & $133(85.3)$ & $46(80.7)$ & $87(87.9)$ & \\
\hline \multicolumn{5}{|l|}{ Pulmonary function test } \\
\hline$\% F V C, \%$ & $70.9 \pm 15.1$ & $73.0 \pm 15.1$ & $69.7 \pm 15.0$ & 0.204 \\
\hline$\%$ FEV1, \% & $80.5 \pm 15.7$ & $81.2 \pm 13.3$ & $80.0 \pm 16.9$ & 0.646 \\
\hline$\% D L C O, \%$ & $54.2 \pm 18.8$ & $54.3 \pm 19.0$ & $54.1 \pm 18.8$ & 0.953 \\
\hline 6MWT, m & $\begin{array}{l}418.5 \pm \\
101.8\end{array}$ & $428.1 \pm 106.5$ & $413.6 \pm 99.5$ & 0.439 \\
\hline $6 \mathrm{MWT}$, the lowest $\mathrm{SpO}_{2}, \%$ & $91.7 \pm 4.7$ & $91.0 \pm 5.5$ & $92.0 \pm 4.2$ & 0.229 \\
\hline $\begin{array}{l}{ }^{*} \text { Pulmonary hypertension, } \mathrm{n} \\
(\%)\end{array}$ & $17(10.9)$ & $6(11.1)$ & $11(10.5)$ & 0.910 \\
\hline Emphysema, n (\%) & $71(45.5)$ & $31(54.4)$ & $40(40.4)$ & 0.091 \\
\hline Co-existing cancer, n (\%) & $62(39.7)$ & $20(35.1)$ & $42(42.4)$ & 0.367 \\
\hline Chemotherapy, n (\%) & $14(9.0)$ & $5(8.8)$ & $9(9.1)$ & 0.946 \\
\hline
\end{tabular}

Data presented as mean \pm standard deviation or number (percentage), unless otherwise indicated.

*Pulmonary hypertension was assessed based on echocardiography.

Abbreviations: 6MWT, 6-minute walking test; BMI, body mass index; DLCO, diffusing capacity for carbon monoxide; $\mathrm{FVC}$, forced vital capacity; $\mathrm{FEV}_{1}$, forced expiratory volume in one second; $\mathrm{SpO}_{2}$, Peripheral oxygen saturation.

\section{Adverse events}

A total of 109 (69.9\%) patients of the total population experienced adverse events. The most frequent adverse events were dyspepsia (19.9\%), urticaria (19.9\%), anorexia (12.8\%), and general weakness $(7.7 \%)$. 
The incidence of anorexia ( $3.5 \%$ vs. $18.2 \%, p=0.008)$, urticaria $(10.5 \%$ vs. $25.3 \%, p=0.026)$, and general weakness $(0.0 \%$ vs. $12.1 \%, p=0.004)$ was higher in the standard dose group than in the low dose group. No significant difference was found in the incidence of dyspepsia, nausea, diarrhea, rash, and photosensitivity between the two groups. However, after categorization of patients by symptoms, more Gl-related adverse events $(p<0.01)$, skin-related adverse events $(p=0.006)$, and uncategorized adverse events $(p=0.001)$ were found in the standard dose group than in the low dose group (Table 2$)$.

Table 2. Adverse events in enrolled patients

\begin{tabular}{|lllll|}
\hline Adverse events, $\mathbf{n}(\%)$ & $\begin{array}{l}\text { Total } \\
(\mathbf{n}=\mathbf{1 5 6})\end{array}$ & $\begin{array}{l}\text { Standard dose group } \\
(\mathbf{n}=\mathbf{5 7})\end{array}$ & $\begin{array}{l}\text { Low dose group } \\
(\mathbf{n}=\mathbf{9 9})\end{array}$ & $\boldsymbol{P}$ value \\
\hline Gastrointestinal & $60(38.5)$ & $9(15.8)$ & $51(51.5)$ & $<0.001$ \\
\hline Dyspepsia & $31(19.9)$ & $7(12.3)$ & $24(24.2)$ & 0.071 \\
\hline Anorexia & $20(12.8)$ & $2(3.5)$ & $18(18.2)$ & 0.008 \\
\hline Nausea & $6(3.8)$ & $0(0.0)$ & $6(6.1)$ & 0.087 \\
\hline Diarrhea & $3(1.9)$ & $0(0.0)$ & $3(3.0)$ & 0.300 \\
\hline Skin & $42(26.9)$ & $8(14.0)$ & $34(34.4)$ & 0.006 \\
\hline Urticaria & $31(19.9)$ & $6(10.5)$ & $25(25.3)$ & 0.026 \\
\hline Rash & $6(3.8)$ & $2(3.5)$ & $4(4.0)$ & $>0.999$ \\
\hline Photosensitivity & $5(3.2)$ & $0(0.0)$ & $5(5.1)$ & 0.159 \\
\hline Others & $17(10.9)$ & $1(1.8)$ & $16(16.2)$ & 0.005 \\
\hline General weakness & $12(7.7)$ & $0(0.0)$ & $12(12.1)$ & 0.004 \\
\hline AST/ALT elevation & $4(2.6)$ & $0(0.0)$ & $4(4.0)$ & 0.297 \\
\hline Azotemia & $1(0.6)$ & $0(0.0)$ & $1(1.0)$ & $>0.999$ \\
\hline Weight loss & $2(1.3)$ & $1(1.8)$ & $1(1.0)$ & $>0.999$ \\
\hline Myalgia & $1(0.6)$ & $0(0.0)$ & $1(1.0)$ & $>0.999$ \\
\hline
\end{tabular}

Abbreviations: AST, aspartate aminotransferase; ALT, alanine aminotransferase.

\section{Factors associated with dose reduction of pirfenidone}

Logistic regression analysis was performed to evaluate the risk factors associated with dose reduction of pirfenidone. In univariate analysis, older age (odds ratio $[\mathrm{OR}]=1.052, p=0.014)$, male $(\mathrm{OR}=0.241, p=$ $0.067)$, ever smoking status ( $\mathrm{OR}=0.146, p=0.012)$, and lower $\mathrm{BMI}(\mathrm{OR}=0.903, p=0.030)$ were associated with dose reduction of pirfenidone. In multivariate logistic regression analysis, older age $(\mathrm{OR}=$ 
$1.060, p=0.014$ ) was significantly associated with dose reduction of pirfenidone after adjusting for sex, ever smoking status, and BMI (Table 3 ).

Table 3. Risk factors for dose reduction of pirfenidone

\begin{tabular}{|llll|}
\hline Parameters & Odds ratio & $95 \%$ confidence interval & P value \\
\hline Univariate analysis & & & \\
\hline Patients, $\mathrm{n}$ & & & \\
\hline Age, years & 1.052 & $1.010-1.096$ & 0.014 \\
\hline Male sex & 0.241 & $0.052-1.107$ & 0.067 \\
\hline Ever-smokers & 0.146 & $0.033-0.652$ & 0.012 \\
\hline BMI, kg/m ${ }^{2}$ & 0.903 & $0.823-0.990$ & 0.030 \\
\hline FVC, \% predicted & 0.986 & $0.964-1.008$ & 0.204 \\
\hline FEV1, \% predicted & 0.995 & $0.974-1.016$ & 0.643 \\
\hline DLCO, \% predicted & 0.999 & $0.982-1.017$ & 0.953 \\
\hline 6MWT, m & 0.999 & $0.995-1.002$ & 0.436 \\
\hline 6MWT, \% & 1.047 & $0.971-1.130$ & 0.229 \\
\hline${ }^{*}$ Pulmonary hypertension & 1.062 & $0.371-3.045$ & 0.910 \\
\hline Emphysema & 0.569 & $0.295-1.098$ & 0.093 \\
\hline Co-existing cancer & 1.363 & $0.695-2.676$ & 0.0631 \\
\hline Chemotherapy & 1.040 & $0.331-3.269$ & 0.946 \\
\hline Multivariate analysis & & & 0.095 \\
\hline Age, years & 1.060 & $1.012-1.110$ & \\
\hline Male sex & 1.905 & $0.138-26.365$ & $0.007-1.157$ \\
\hline Ever-smokers & 0.093 & 0.005 & \\
\hline BMl, kg/m ${ }^{2}$ & 0.920 & $0.834-1.015$ & \\
\hline
\end{tabular}

*Pulmonary hypertension was assessed based on echocardiography.

Abbreviations: 6MWT, 6-minute walking test; BMI, body mass index; DLCO, diffusing capacity for carbon monoxide; FVC, forced vital capacity; $F_{1} V_{1}$ forced expiratory volume in one second. 
We compared the differences between patients aged $\geq 70$ years (old age group) and those aged $<70$ years (young age group). No significant difference in sex ratio, smoking history, and BMI was found between the two groups. Among adverse events, anorexia $(p=0.042)$ occurred more frequently in the old age group than in the young age group (Table 4).

Table 4. Comparison of baseline characteristics and adverse events according to age

\begin{tabular}{|lllll|}
\hline & $\begin{array}{l}\text { Total } \\
(\mathbf{n = 1 5 6})\end{array}$ & $\begin{array}{l}\text { Age } \mathbf{2 7 0} \text { years } \\
(\mathbf{n}=\mathbf{8 4})\end{array}$ & $\begin{array}{l}\text { Age }<70 \text { years } \\
(\mathbf{n}=\mathbf{7 2})\end{array}$ & P value \\
\hline Male, $\mathrm{n}(\%)$ & $141(90.4)$ & $77(91.7)$ & $64(88.9)$ & 0.557 \\
\hline Ever-smoker, $\mathrm{n}(\%)$ & $133(85.8)$ & $72(86.7)$ & $61(84.7)$ & 0.719 \\
\hline BMI, kg/m ${ }^{2}$ & $24.7 \pm 4.0$ & $24.4 \pm 4.4$ & $25.1 \pm 3.5$ & 0.256 \\
\hline Gastrointestinal & $60(38.5)$ & $34(40.5)$ & $26(36.1)$ & 0.576 \\
\hline Dyspepsia & $31(19.9)$ & $14(16.7)$ & $17(23.6)$ & 0.279 \\
\hline Anorexia & $20(12.8)$ & $15(17.9)$ & $5(6.9)$ & 0.042 \\
\hline Nausea & $6(3.8)$ & $5(6.0)$ & $1(1.4)$ & 0.218 \\
\hline Diarrhea & $3(1.9)$ & $0(0.0)$ & $3(4.2)$ & 0.096 \\
\hline Skin & $42(26.9)$ & $22(26.2)$ & $20(27.8)$ & 0.824 \\
\hline Urticaria & $31(19.9)$ & $16(19.0)$ & $15(20.8)$ & 0.781 \\
\hline Rash & $6(3.8)$ & $3(3.6)$ & $3(4.2)$ & $>0.999$ \\
\hline Photosensitivity & $5(3.2)$ & $3(3.6)$ & $2(2.8)$ & $>0.999$ \\
\hline Others & $17(10.9)$ & $10(11.9)$ & $7(9.7)$ & 0.663 \\
\hline General weakness & $12(7.7)$ & $9(10.7)$ & $3(4.2)$ & 0.126 \\
\hline AST/ALT elevation & $4(2.6)$ & $1(1.2)$ & $3(4.2)$ & 0.336 \\
\hline Azotemia & $1(0.6)$ & $1(1.2)$ & $0(0.0)$ & $>0.999$ \\
\hline Weight loss & $2(1.3)$ & $1(1.2)$ & $1(1.4)$ & $>0.999$ \\
\hline Myalgia & $1(0.6)$ & $1(1.2)$ & $0(0.0)$ & $>0.999$ \\
\hline
\end{tabular}

Results presented as means \pm standard deviations or number of patients $(\%)$, unless otherwise indicated. Abbreviations: AST, aspartate aminotransferase; ALT, alanine aminotransferase; BMI, body mass index. 
A total of $26(16.7 \%)$ patients discontinued pirfenidone and 130 (83.3\%) patients continued pirfenidone. No significant differences in baseline characteristics were found between patients who discontinued pirfenidone and those who continued pirfenidone. Considering adverse events, general weakness ( $p=$ 0.030 ) was significantly higher in patients who discontinued pirfenidone than in those who continued pirfenidone. After classification of adverse events according to symptoms, skin-related $(p=0.053)$ adverse events and uncategorized $(p=0.040)$ adverse events occurred more frequently in patients who discontinued the drug than in patients who continued the drug (Table 5). Logistic regression analysis was performed to evaluate the risk factors for discontinuation of pirfenidone. Skin-related adverse events ( $p=$ $0.033)$ and uncategorized adverse events $(p=0.025)$ were significantly associated with discontinuation of pirfenidone after adjusting for ever smoking status (Supplementary Table 2).

Table 5. Comparison of baseline characteristics and adverse events between patients who continued and discontinued pirfenidone 


\begin{tabular}{|c|c|c|c|c|}
\hline & $\begin{array}{l}\text { Total } \\
(n=156)\end{array}$ & $\begin{array}{l}\text { Continued pirfenidone } \\
(n=130)\end{array}$ & $\begin{array}{l}\text { Discontinued pirfenidone } \\
(n=26)\end{array}$ & $P$ value \\
\hline Age, years & $69.7 \pm 8.5$ & $69.4 \pm 8.6$ & $70.8 \pm 8.5$ & 0.449 \\
\hline Male, n (\%) & $141(90.4)$ & $117(90.0)$ & $24(92.3)$ & $>0.999$ \\
\hline Ever-smoker, n (\%) & $133(85.8)$ & $113(85.0)$ & $20(76.9)$ & 0.213 \\
\hline $\mathrm{BMI}, \mathrm{kg} / \mathrm{m}^{2}$ & $24.7 \pm 4.0$ & $24.8 \pm 4.2$ & $24.5 \pm 2.9$ & 0.698 \\
\hline Gastrointestinal & $60(38.5)$ & $49(37.7)$ & $11(42.3)$ & 0.659 \\
\hline Dyspepsia & $31(19.9)$ & $26(20.0)$ & $5(19.2)$ & 0.929 \\
\hline Anorexia & $20(12.8)$ & $17(13.1)$ & $3(11.5)$ & $>0.999$ \\
\hline Nausea & $6(3.8)$ & $4(3.1)$ & $2(7.7)$ & 0.262 \\
\hline Diarrhea & $3(1.9)$ & $2(1.5)$ & $1(3.8)$ & 0.424 \\
\hline Skin & $42(26.9)$ & $31(23.8)$ & $11(42.3)$ & 0.053 \\
\hline Urticaria & 31 (19.9) & $24(18.5)$ & 7 (26.9) & 0.324 \\
\hline Rash & $6(3.8)$ & $4(3.1)$ & $2(7.7)$ & 0.262 \\
\hline Photosensitivity & $5(3.2)$ & $3(2.3)$ & $2(7.7)$ & 0.194 \\
\hline Others & $17(10.9)$ & $11(8.5)$ & $6(23.1)$ & 0.040 \\
\hline General weakness & $12(7.7)$ & $7(5.4)$ & $5(19.2)$ & 0.030 \\
\hline AST/ALT elevation & $4(2.6)$ & $2(1.5)$ & $2(7.7)$ & 0.130 \\
\hline Azotemia & $1(0.6)$ & $0(0.0)$ & $1(3.8)$ & 0.167 \\
\hline Weight loss & $2(1.3)$ & $1(0.8)$ & $1(3.8)$ & 0.306 \\
\hline Myalgia & $1(0.6)$ & $1(0.8)$ & $0(0.0)$ & $>0.999$ \\
\hline
\end{tabular}

Data are presented as mean \pm standard deviation or number of patients $(\%)$, unless otherwise indicated. Abbreviations: AST, aspartate aminotransferase; ALT, alanine aminotransferase; BMI, body mass index.

\section{Efficacy of low dose pirfenidone in IPF}

To evaluate the efficacy of low-dose pirfenidone on disease progression, we compared the changes in lung function using FVC and DLCO changes between the standard and low dose groups. FVC and DLCO changes after treatment were investigated in patients with data of at least two PFTs, at baseline and after treatment. No significant difference was found in the reduction rate of $\operatorname{FVC}(p=0.260)$ and DLCO $(p=$ 0.186 ) between the two groups (Figure 2). 


\section{Discussion}

In the present real-world study, 109 (69.9\%) patients experienced side effects and 99 (63.5\%) patients did not receive higher doses of pirfenidone up to $1800 \mathrm{mg} /$ day or decreased dosage during the follow-up period. Old age was an independent risk factor for dose reduction of pirfenidone; however, no significant difference was found in lung function change between the standard and low dose groups.

In previous prospective clinical studies (CAPACITY trials), 98\% patients reported treatment-related adverse events. The most common adverse events were nausea (36\%), rash (32\%), and dyspepsia (19\%) [4]. Similarly, in the pirfenidone use group in the ASCEND trial, $36 \%$ of patients experienced nausea and $28.1 \%$ developed a rash. In that study, adverse events occurred more frequently in the pirfenidone use group than in the placebo group, in which $13.4 \%$ of patients experienced nausea and $8.7 \%$ developed rash [5]. However, Taniguchi et al. reported that photosensitivity was the most common adverse event in the study population of 267 Japanese patients with IPF, which was $51 \%$ in the high-dose group and $53 \%$ in the low dose group [12]. Oltmannus et al. reported that 52 (85\%) of patients experienced adverse events, including fatigue (54\%), weight loss (30\%), and skin reaction (28\%), in real-world practice in Germany [18]. A PMS study in Japan reported that $64.6 \%$ of patients experienced side effects [19]. In a single-center study in China, $43.6 \%$ of patients with IPF experienced adverse events, which included GI related (35\%) and skin related (20.5\%) adverse events [20]. In the current study, 109 (69.9\%) patients experienced adverse events, 60 (38.5\%) of whom experienced Gl-related adverse events and 42 (26.9\%) experienced skin-related adverse events. Hence, there is a possibility that the side effects of pirfenidone may differ between races and may occur at a higher frequency in real world practice than in RCTs.

Based on real-world data, dose reduction of pirfenidone is common [21-25]. Salih et al. reported that of 113 patients with IPF who were treated with pirfenidone, 51 (45.2\%) required dose adjustment and 18 (16\%) discontinued the treatment [21]. In addition, Dbooria et al. reported that of 115 patients with IPF who were treated with pirfenidone, only 49 (42.6\%) patients tolerated the full dose ( $2400 \mathrm{mg} / \mathrm{day})$ and 51 $(44.3 \%)$ patients tolerated the reduced dose [22]. Although the maximal dose of pirfenidone in Asia is $1800 \mathrm{mg}$, it has been reported that few patients are actually taking the maximal dose [14, 19]. Indeed, in our study, 99 (63.5\%) patients belonged to the low dose group, which is comparable to that reported in previous studies. Although dose adjustment of pirfenidone is known as a method to reduce the occurrence of drug-related adverse events and risk of drug discontinuation [23, 24], few studies have investigated the requirements of dose adjustment and risk factors for dose reduction. However, Uehara et al. suggested that an adjusted dose of pirfenidone for body surface area or body weight could reduce adverse events and promote continued treatment of pirfenidone based on the data of a small number of patients [25]. In the current study, old age was an independent risk factor for pirfenidone dose reduction. Considering the findings of previous reports that elderly patients usually experience drug side effects [26, 27], it may be necessary to carefully monitor adverse events, especially in elderly patients with IPF who receive pirfenidone. 
In the current study, 26 (16.7\%) patients discontinued pirfenidone. The rate of discontinuation of the drug was comparable to that reported in previous studies. In a prospective study by Dhooria et al., 22 (19.1\%) patients discontinued the treatment [22]. A study assessing the real-world data of pirfenidone in Germany reported that 18 (15.4\%) patients discontinued pirfenidone. In a study in Greece, 9 (20.9\%) patients discontinued the treatment[28]. However, the risk factors for discontinuation of pirfenidone are not well known. A study reported that low BMI is a predictor for drug discontinuation because of adverse events [22]. Another study reported that older age, use of steroids prior to the study, and female sex are associated with early termination of the treatment [29]. In our study, patients who experienced skin-related or uncategorized adverse events were significantly more likely to discontinue the drug. However, few patients discontinued pirfenidone in our study. Further large-scale studies investigating the risk factors for discontinuation are warranted.

In a pooled analysis of multinational phase III trials, efficacy of pirfenidone was compared between patients according to dose intensity $(>90 \%$ and $\leq 90 \%)$. The study reported that regardless of dose intensity, the pirfenidone group had significantly lower annual rate of FVC decline than the placebo group [23]. Another phase III trial in Japan reported a significant difference in vital capacity (approximately 0.07 L) between the high-dose $(1800 \mathrm{mg} /$ day $)$ and placebo groups $(p=0.0416)$ and significant difference in vital capacity (approximately $0.09 \mathrm{~L}$ ) between the low dose $(1200 \mathrm{mg} /$ day) and placebo groups $(p=$ $0.0394)$, suggesting that low-dose pirfenidone is effective [12]. A study assessing the real-world data of

pirfenidone in South Korea reported that relatively a low dose of pirfenidone ( $\leq 1200 \mathrm{mg} / \mathrm{day}$ ) can have an effect on pulmonary function decline $[14,15]$. In our study, we compared FVC and DLCO changes between the standard and low dose groups and found no significant difference in efficacy with dose, which is comparable to that reported in previous studies. Unexpectedly, the change in DLCO at 12 months was not statistically significantly higher, but tended to be higher in the low dose group than in the standard-dose group. This is because emphysema was more common in the standard dose group, which may result in lower DLCO. Based on the results of our study, low-dose pirfenidone treatment might be an effective treatment strategy, especially in elderly patients.

This study has several limitations. First, this study was a single center retrospective study. Second, because patients visited the hospital intermittently and self-reported adverse events, recall bias may exist. Third, not all patients underwent follow-up PFTs, limiting the evaluation of pirfenidone efficacy. Fourth, the follow-up period was relatively short. In a previous post-hoc analysis, the median time to the first adverse event leading to dose modification was 62 days [30]. Therefore, a short follow-up period did not significantly affect the evaluation of adverse events; however, it may have affected the evaluation of disease progression.

\section{Conclusion}

The present study revealed that older patients are more likely than younger patients to undergo dose reduction of pirfenidone. Thus, monitoring whether older people experience side effects and show poor compliance is essential. No difference was found in the effect of pirfenidone between the standard and 
low dose groups; hence, low dose pirfenidone can be considered effective, especially for the treatment of older patients with IPF.

\section{List Of Abbreviations}

alanine aminotransferase (ALT)

aspartate aminotransferase (AST)

body mass index (BMI)

diffusing capacity of the lungs for carbon monoxide (DLCO)

electronic medical record (EMR)

forced expiratory volume in one second (FEV1)

Forced vital capacity (FVC)

high-resolution computed tomography (HRCT)

idiopathic pulmonary fibrosis (IPF)

interquartile range (IQR)

Institutional Review Board (IRB)

maximal tricuspid regurgitation velocity (TR Vmax)

odds ratio (OR)

pulmonary function test (PFT)

post-marketing surveillance (PMS)

Peripheral oxygen saturation (SpO2)

randomized controlled trial (RCT)

six-minute walk test (6MWT)

\section{Declarations}

\section{Ethics approval and consent to participate}


The study protocol was approved by the Institutional Review Board of Asan Medical Center (approval number: 2021-0787), and the requirement for written informed consent was waived owing to the retrospective nature of the study.

\section{Consent for publication}

Not applicable.

\section{Availability of data and materials}

Not applicable.

\section{Competing interests}

The authors declare that they have no competing interests.

\section{Funding}

None.

\section{Authors' contributions}

$\mathrm{KJ}, \mathrm{CC}$, and $\mathrm{KHC}$ were involved in developing the concept and design of the study. $\mathrm{KJ}, \mathrm{CC}$, and $\mathrm{CHS}$ were involved in data acquisition, analysis, and interpretation. KJ and $\mathrm{KHC}$ drafted the manuscript. All authors read revised and approved the final manuscript.

\section{Acknowledgements}

Not applicable.

\section{References}

1. Raghu G, Remy-Jardin M, Myers JL, Richeldi L, Ryerson CJ, Lederer DJ, Behr J, Cottin V, Danoff SK, Morell F, et al: Diagnosis of Idiopathic Pulmonary Fibrosis. An Official ATS/ERS/JRS/ALAT Clinical Practice Guideline. Am J Respir Crit Care Med 2018, 198:e44-e68.

2. Mapel DW, Hunt WC, Utton R, Baumgartner KB, Samet JM, Coultas DB: Idiopathic pulmonary fibrosis: survival in population based and hospital based cohorts. Thorax 1998, 53:469-476.

3. Ley B, Collard HR, King TE, Jr.: Clinical course and prediction of survival in idiopathic pulmonary fibrosis. Am J Respir Crit Care Med 2011, 183:431-440.

4. Noble PW, Albera C, Bradford WZ, Costabel U, Glassberg MK, Kardatzke D, King TE, Jr., Lancaster L, Sahn SA, Szwarcberg J, et al: Pirfenidone in patients with idiopathic pulmonary fibrosis (CAPACITY): two randomised trials. Lancet 2011, 377:1760-1769. 
5. King TE, Jr., Bradford WZ, Castro-Bernardini S, Fagan EA, Glaspole I, Glassberg MK, Gorina E, Hopkins PM, Kardatzke D, Lancaster L, et al: A phase 3 trial of pirfenidone in patients with idiopathic pulmonary fibrosis. N Engl J Med 2014, 370:2083-2092.

6. Krauss E, Tello S, Wilhelm J, Schmidt J, Stoehr M, Seeger W, Dartsch RC, Crestani B, Guenther A: Assessing the Effectiveness of Pirfenidone in Idiopathic Pulmonary Fibrosis: Long-Term, Real-World Data from European IPF Registry (eurIPFreg). J Clin Med 2020, 9.

7. Zurkova M, Kriegova E, Kolek V, Lostakova V, Sterclova M, Bartos V, Doubkova M, Binkova I, Svoboda M, Strenkova J, et al: Effect of pirfenidone on lung function decline and survival: 5-yr experience from a real-life IPF cohort from the Czech EMPIRE registry. Respir Res 2019, 20:16.

8. Margaritopoulos GA, Trachalaki A, Wells AU, Vasarmidi E, Bibaki E, Papastratigakis G, Detorakis S, Tzanakis N, Antoniou KM: Pirfenidone improves survival in IPF: results from a real-life study. BMC Pulm Med 2018, 18:177.

9. Nathan SD, Albera C, Bradford WZ, Costabel U, Glaspole I, Glassberg MK, Kardatzke DR, Daigl M, Kirchgaessler KU, Lancaster LH, et al: Effect of pirfenidone on mortality: pooled analyses and metaanalyses of clinical trials in idiopathic pulmonary fibrosis. Lancet Respir Med 2017, 5:33-41.

10. Jiang C, Huang H, Liu J, Wang Y, Lu Z, Xu Z: Adverse events of pirfenidone for the treatment of pulmonary fibrosis: a meta-analysis of randomized controlled trials. PLoS One 2012, 7:e47024.

11. Lancaster LH, de Andrade JA, Zibrak JD, Padilla ML, Albera C, Nathan SD, Wijsenbeek MS, Stauffer $\mathrm{JL}$, Kirchgaessler KU, Costabel U: Pirfenidone safety and adverse event management in idiopathic pulmonary fibrosis. Eur Respir Rev 2017, 26.

12. Taniguchi H, Ebina M, Kondoh Y, Ogura T, Azuma A, Suga M, Taguchi Y, Takahashi H, Nakata K, Sato A, et al: Pirfenidone in idiopathic pulmonary fibrosis. Eur Respir J 2010, 35:821-829.

13. Chung MP, Park MS, Oh IJ, Lee HB, Kim YW, Park JS, Uh ST, Kim YS, Jegal Y, Song JW: Safety and Efficacy of Pirfenidone in Advanced Idiopathic Pulmonary Fibrosis: A Nationwide Post-Marketing Surveillance Study in Korean Patients. Adv Ther 2020, 37:2303-2316.

14. Song MJ, Moon SW, Choi JS, Lee SH, Lee SH, Chung KS, Jung JY, Kang YA, Park MS, Kim YS, et al: Efficacy of low dose pirfenidone in idiopathic pulmonary fibrosis: real world experience from a tertiary university hospital. Sci Rep 2020, 10:21218.

15. Lee EG, Lee TH, Hong Y, Ryoo J, Heo JW, Gil BM, Kang HS, Kwon SS, Kim YH: Effects of low-dose pirfenidone on survival and lung function decline in patients with idiopathic pulmonary fibrosis (IPF): Results from a real-world study. PLoS One 2021, 16:e0261684.

16. Rudski LG, Lai WW, Afilalo J, Hua L, Handschumacher MD, Chandrasekaran K, Solomon SD, Louie EK, Schiller NB: Guidelines for the echocardiographic assessment of the right heart in adults: a report from the American Society of Echocardiography endorsed by the European Association of Echocardiography, a registered branch of the European Society of Cardiology, and the Canadian Society of Echocardiography. J Am Soc Echocardiogr 2010, 23:685-713; quiz 786-688.

17. Lang RM, Badano LP, Mor-Avi V, Afilalo J, Armstrong A, Ernande L, Flachskampf FA, Foster E, Goldstein SA, Kuznetsova T: Recommendations for cardiac chamber quantification by 
echocardiography in adults: an update from the American Society of Echocardiography and the European Association of Cardiovascular Imaging. European Heart Journal-Cardiovascular Imaging 2015, 16:233-271.

18. Oltmanns U, Kahn N, Palmowski K, Träger A, Wenz H, Heussel CP, Schnabel PA, Puderbach M, Wiebel M, Ehlers-Tenenbaum S, et al: Pirfenidone in Idiopathic Pulmonary Fibrosis: Real-Life Experience from a German Tertiary Referral Center for Interstitial Lung Diseases. Respiration 2014, 88:199-207.

19. Ogura T, Azuma A, Inoue $Y$, Taniguchi H, Chida K, Bando M, Niimi Y, Kakutani S, Suga M, Sugiyama $Y$, et al: All-case post-marketing surveillance of 1371 patients treated with pirfenidone for idiopathic pulmonary fibrosis. Respir Investig 2015, 53:232-241.

20. Fang $C$, Huang H, Guo J, Ferianc M, Xu Z: Real-world experiences: Efficacy and tolerability of pirfenidone in clinical practice. PLoS One 2020, 15:e0228390.

21. Salih GN, Shaker SB, Madsen HD, Bendstrup E: Pirfenidone treatment in idiopathic pulmonary fibrosis: nationwide Danish results. Eur Clin Respir J 2016, 3:32608.

22. Dhooria S, Agarwal R, Sehgal IS, Prasad KT, Muth V, Garg M, Bal A, Aggarwal AN, Behera D: A realworld study of the dosing and tolerability of pirfenidone and its effect on survival in idiopathic pulmonary fibrosis. Sarcoidosis Vasc Diffuse Lung Dis 2020, 37:148-157.

23. Nathan SD, Lancaster LH, Albera C, Glassberg MK, Swigris JJ, Gilberg F, Kirchgaessler KU, Limb SL, Petzinger U, Noble PW: Dose modification and dose intensity during treatment with pirfenidone: analysis of pooled data from three multinational phase III trials. BMJ Open Respir Res 2018, 5:e000323.

24. Costabel U, Bendstrup E, Cottin V, Dewint P, Egan JJ, Ferguson J, Groves R, Hellstrom PM, Kreuter M, Maher TM, et al: Pirfenidone in idiopathic pulmonary fibrosis: expert panel discussion on the management of drug-related adverse events. Adv Ther 2014, 31:375-391.

25. Uehara M, Enomoto N, Oyama Y, Suzuki Y, Kono M, Furuhashi K, Fujisawa T, Inui N, Nakamura Y, Suda T: Body size-adjusted dose analysis of pirfenidone in patients with interstitial pneumonia. Respirology 2018, 23:318-324.

26. Tangiisuran B, Wright J, Van der Cammen T, Rajkumar C: Adverse drug reactions in elderly: challenges in identification and improving preventative strategies. Age and Ageing 2009, 38:358-359.

27. Tangiisuran $B$, Wright $J$, Van der Cammen T, Rajkumar $C$ : Adverse drug reactions in elderly: challenges in identification and improving preventative strategies. Age Ageing 2009, 38:358-359.

28. Tzouvelekis A, Ntolios P, Karampitsakos T, Tzilas V, Anevlavis S, Bouros E, Steiropoulos P, Koulouris N, Stratakos G, Froudarakis M, Bouros D: Safety and efficacy of pirfenidone in severe Idiopathic Pulmonary Fibrosis: A real-world observational study. Pulm Pharmacol Ther 2017, 46:48-53.

29. Cottin V, Koschel D, Gunther A, Albera C, Azuma A, Skold CM, Tomassetti S, Hormel P, Stauffer JL, Strombom I, et al: Long-term safety of pirfenidone: results of the prospective, observational PASSPORT study. ERJ Open Res 2018, 4.

30. Mason WR, Nathan SD, Zibrak JD, Padilla ML, Gilberg F, Petzinger U, Kirchgaessler K, Lancaster LH: Time-to-event analysis of common adverse events with pirfenidone in patients with IPF- a pooled 
analysis of three phase III clinical trials. American Journal of Respiratory and Critical Care Medicine 2017, 195.

Figures

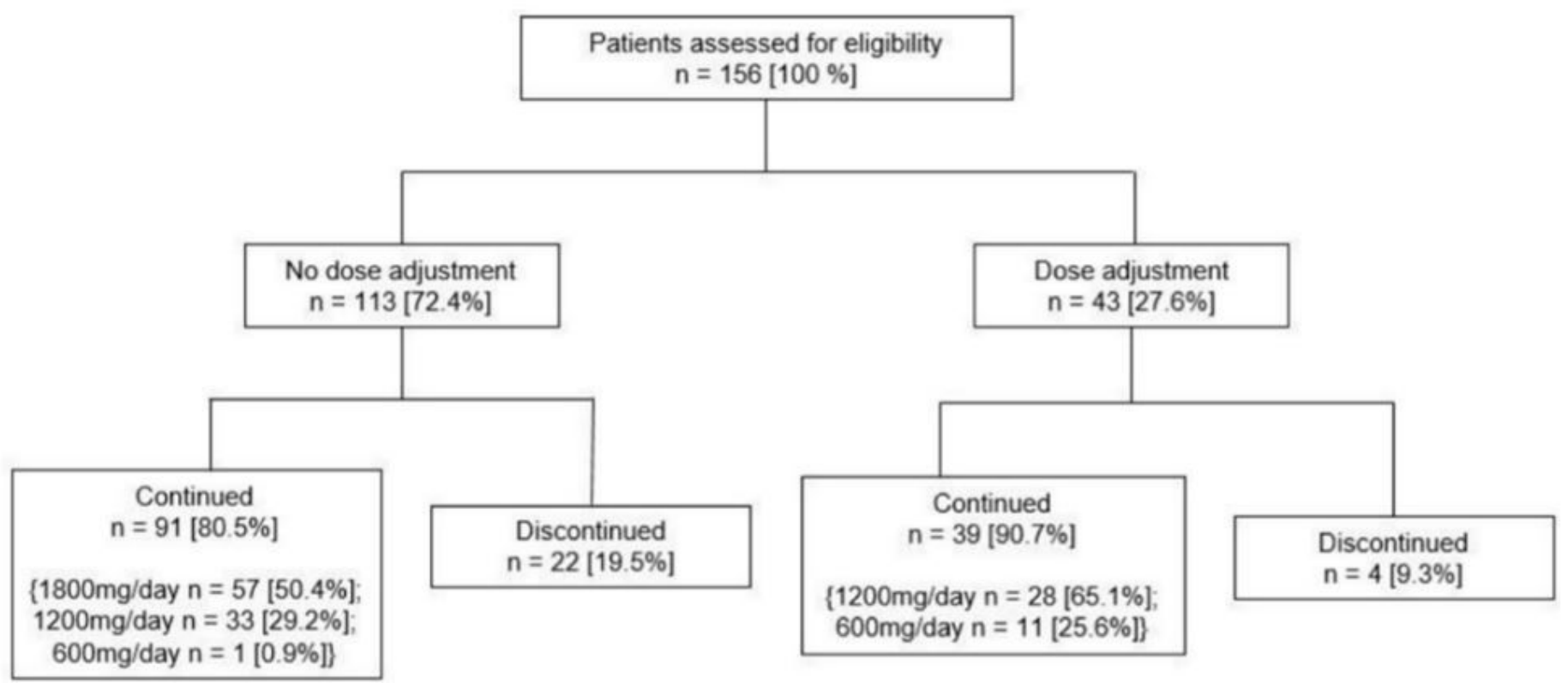

Figure 1

Patient disposition

(a) $\%$ FVC



(b) \%DLco

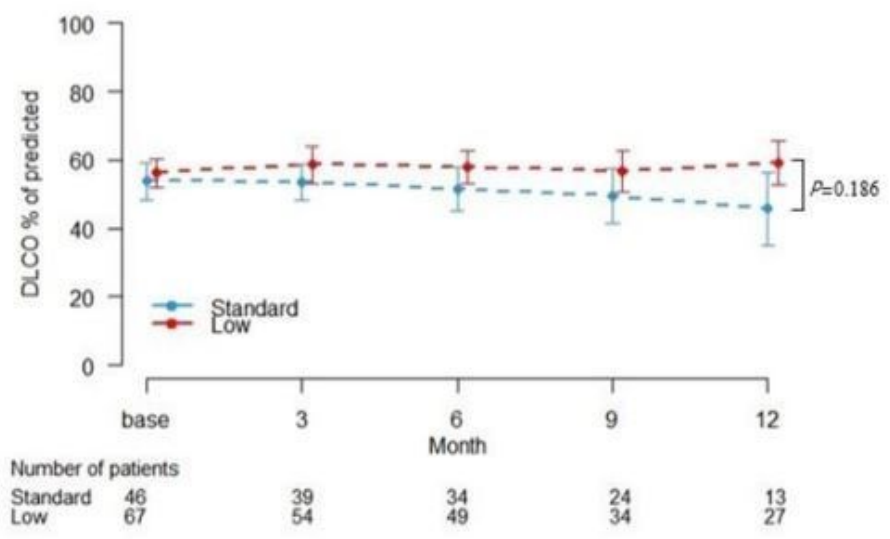

\section{Figure 2}

Changes in FVC and DLCO according to pirfenidone dose: (a) \%FVC ( $p=0.260)$; (b) \% DLCO $(p=0.186)$ 
Abbreviations: DLCO, diffusing capacity for carbon monoxide; FVC, forced vital capacity.

\section{Supplementary Files}

This is a list of supplementary files associated with this preprint. Click to download.

- SupplementaryTable1.docx

- SupplementaryTable2.docx 